\title{
Impact of Covid-19 on the dynamics of MTPL insurance premiums and claims paid in Latvia
}

\author{
AIVARS SPILBERGS \\ Department of Economics and Finance \\ BA School of Business and Finance \\ 161 Kr.Valdemara str., Riga \\ LATVIA \\ ANDRIS FOMINS \\ Department of Economics and Finance \\ BA School of Business and Finance \\ $161 \mathrm{Kr}$.Valdemara str., Riga \\ LATVIA \\ MARIS KRASTINS \\ Department of Economics and Finance \\ BA School of Business and Finance \\ 161 Kr.Valdemara str., Riga \\ LATVIA
}

\begin{abstract}
COVID-19 has devastated societies and economies around the world, leaving no sector untouched. The unprecedented crisis caused by Covid-19 led to unexpected changes in public behaviour: the restrictions imposed, especially during the pandemic outbreaks in March-April and November-December 2020, left a significant impact on traffic volumes. By the spring of 2020, more than half of the world's population had been isolated with tough containment measures. Opportunities to work from home reduced the need to use private cars and, consequently, the demand for motor third party liability (MTPL) insurance. In order to understand the significance of the impact of the pandemic on MTPL insurance premiums and claims, the authors studied the impact of macroeconomic factors on the insurance market in Latvia in the period from 2005-2020. Using regression analysis methods, the evidence was obtained that changes in the macroeconomic situation significantly affect one of the main non-life insurance segments MTPL insurance. A set of indicators, that most significantly affect revenues and expenses in this business segment of insurance companies, was determined. The findings provide useful recommendations for insurance companies to reduce business risks and promote sustainable development. The results of the study are important for insurance-related econometric analysis, investment decisions, forecasting, and policy development.
\end{abstract}

Key-Words: - MTPL insurance, Covid-19, macroeconomic factors, insurance premiums and claims, correlation analysis, regression models and parameters statistical stability.

Received: February 25, 2021. Revised: June 30, 2021. Accepted: July 2, 2021. Published: July 6, 2021.

\section{Introduction}

The nature of the COVID-19 crisis is unprecedented: beyond short-term recurring shocks to health and economics, the long-term impact on human capital, productivity and behaviour can be long-term. The COVID crisis has significantly accelerated some of the existing trends, in particular, digitalization. It shocked the world, setting in motion waves of change with a wide range of possible trajectories. 
The stationarity of insurance premiums affects the forecasts of insurance companies about the future inflow of insurance premiums, which affects the liquidity of insurance companies and their investment plans and, thus, is relevant to the activities of insurers. From the comments proposed by Chien-Chang, macroeconomic series are usually affected by exogenous shocks or regime changes in socio-economic events [3].

Figure 1 shows the changing nature of the Latvian MTPL insurance market in terms of both insurance premiums and claims, as well the high loss ratio over a long period of time from 2011-2016., that demonstrates market saturation and strong competition. Covid-19 has significantly affected the MTPL market in Latvia in 2020. The MTPL gross premiums written have decreased by $18.5 \%$, compared to 2019 [17]. At the same time, the claims paid amount for valid policies has decreased by only $6.2 \%$ and thus leaving a significant impact on the performance of insurance companies.

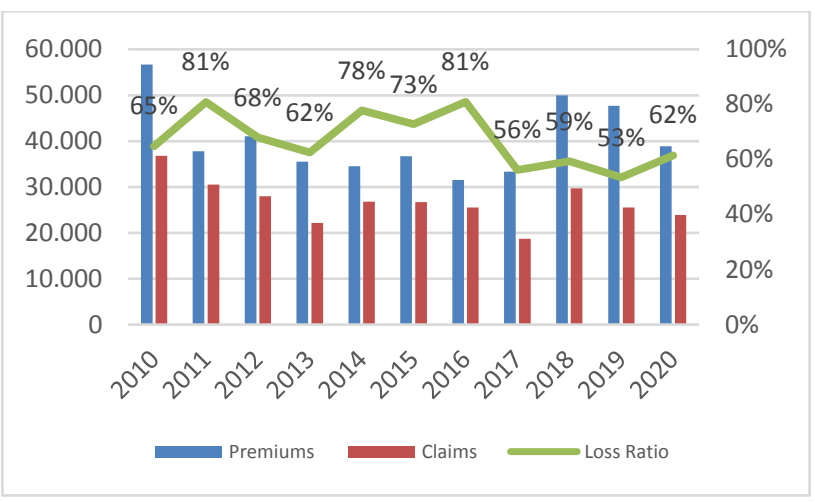

Fig. 1. Gross written premiums, paid claims (thousand EUR) and loss ratio (\%) on MTPLI. Source: [17]

In addition, it should be noted that the coefficient of variation of MTPL claims against premiums has been $63 \%$ higher than in the insurance sector as a whole over the last eleven years. Therefore, it can be concluded that business risk in this segment is significant and therefore it is important to understand the interconnections and be able to make reasonable cash flow forecasts, especially in periods when the economic situation is changing rapidly.

\section{Literature review}

Numerous studies have been conducted on the relationship between insurance development and economic growth. However, the effects of this mechanism differ depending on the analyzed parts of the insurance market, as well as in different countries [14]. There is a limited amount of countryspecific research. Nor do scientists pay attention to the relationship between economic development and insurance market shares. Therefore, the aim of this article was to analyze the motor third party liability insurance and focus on the factors that influence the development of this product in the context of economic development. Since insurance premium rates are usually based on projected investment income and expected losses, which are subject to business cycles, it may be reasonable to expect a significant interrelationship between the activities of insurance markets and macroeconomics [3].

\subsection{GDP, economic growth and financial development impact on MTPLI.}

Significant indicators characterizing the development of the financial sector, which have the strongest correlation with the gross domestic product per capita in the countries with formed bank-based financial system alongside with banking sector size development indicators are insurance sector activity development indicators, such as Nonlife insurance premium volume /GDP [7]. Feyen, et al. found that $1 \%$ increase in GDP is associated with a $0.14 \%$ increase of non-life insurance, which is significantly lower than for life insurance [5]. Cavalcante et al. (2018) investigated, how economic growth and financial development promoted nonlife insurance market. This study analysed the relationship of economic growth and financial development as determinant drivers of non-life insurance consumption in Brazil, based on 1996 and 2016 data and proved the importance of non-life insurance market as a relevant figure for economic growth and financial development, as these factors drive the demand for insurance, which, in turn, feeds back economic activity. The results of the research demonstrated the existence relationship between economic growth and non-life insurance premiums, supporting the existence of the supplyleading phenomenon, in which the growth of the non-life insurance market drives economic growth, and the demand-leading phenomenon, in which economic growth drives the insurance market. The study showed that credit operations cause non-life insurance awards in a unidirectional way, thereby also highlighting the occurrence of the demandfollowing phenomenon in which financial development, represented by the credit, drives the Brazilian insurance market [2]. 
Pradhan et al. reported presence of causality between non-life market density and GDP per capita [11]. There is bidirectional causality between banking competition and economic growth in the presence of insurance market development and stock market development. There is bidirectional causality between stock market development and economic growth and between insurance market development and stock market development, and unidirectional causality from stock market development to insurance market development. The long-term economic growth of European countries depends on the competition in the banking sector, coupled with a well-developed insurance market and a vibrant stock market.

\subsection{Influence of income change on MTPLI premiums}

Previous research has argued that consumption tends to increase with income, creating more demand for insurance. Thus, more income may allow the capitalist to channel a larger share of the profits and investment-related insurance products towards securing the property [3]. Dragos estimated that income, education and urbanisation are important factors of influence for non-life insurance demand, based on data from 17 emerging economies from Asia and Europe [4]. Lee and Chiu found nonlinear relationship between non-life insurance premiums and real income per capita as well as that real non-life insurance premiums are slightly higher than real life insurance premiums [8]. There are high positive correlations between life and non-life insurance premiums and real GDP per capita, suggesting that people will increase their demand for life and non-life insurance products as real income rises. The impact of real GDP on non-life insurance premiums showed U-shaped pattern. The income elasticities of life and non-life insurance premiums are respectively less and larger than 1 . This means that life insurance is a necessary good, and that non-life insurance is a luxury good. There is some difference in the adjustment speed with which real income signals a change in regime for life and non-life insurance premiums, specifically demonstrating that a threshold may exist such that it highlights a transition from one regime to another. The results indicate that the elasticities of life and non-life insurance premiums with respect to real income are heterogeneous across countries, which may be due to the different economic and financial developments of the selected countries [8].
Nakata and Sawada tested a model including income per capita. They concluded that insurance demand is crucially affected by the loss exposure. The latter is affected by the structure of the economy [9]. Sherden finds that the demand for motor insurance is generally inelastic with respect to price and income, and that the demand for comprehensive and collision coverage increases substantially with increased population density [13]. Trinh, C.T. et al. investigation indicates that the level of urbanization has impact on demand for nonlife insurance [15]. A number of works report an apparently pathological result that insurance is a luxury good, i.e. the income elasticity of insurance demand is greater than unity [9].

\subsection{Fleet of cars as a MTPLI market driver.}

Feyen, et al. found that fleet of cars is important driver of non-life sector. The study confirms that influence of cars penetration is positive and highly statistically significant. $1 \%$ increase in number of passenger vehicles per 1,000 inhabitants is associated with a $0.19 \%$ increase of non-life insurance. The regressions for the non-life sector also show that the fleet of cars and the volume of trade are important drivers of the sector's development [5]. Petkovski, M. and Jordan, K. based on investigation of non-life insurance consumption in 16 Central and South-Eastern Europe countries revealed that GDP per capita and number of passengers cars per thousand people has positive and significant impact on non-life insurance demand. They find that non-life insurance penetration increase with higher per-capita income and the number of passenger cars per 1,000 people, which have positively and significantly influence of non-life insurance consumption in 16 countries in the CSEE [10].

The variety of results presented in studies, which differ from country to country and from the analyzed types of insurance market (life and nonlife insurance), indicates the need for additional research on the relationship between the insurance market, economic growth, and financial development. Therefore, using data from the Latvian insurance market, we try to study the relationship between economic growth, financial development and insurance markets, in particular the MTPL insurance market.

There are three main reasons for the importance of testing the stationarity hypothesis. First, this hypothesis test lets you know if a shock has a 
permanent or temporary effect on premiums. Further, the hypothesis of stationarity has direct implications for the hypothesis of convergence of insurance premiums. Third, the stationarity hypothesis has clear implications for econometric modelling. For example, one section of the insurance literature examines the long-term relationship between premiums and macroeconomics

Based on the results of the previous studies, we can put forward the following hypotheses:

1) $H(1)_{0}$ : The macroeconomic situation does not have a significant impact on the amount of MTPLI premiums;

$H(1)_{\mathrm{A}}$ : The macroeconomic situation has a significant impact on the amount of MTPLI premiums;

2) $H(2)_{0}$ : The macroeconomic situation does not have a significant impact on changes in the amount of MTPLI premiums;

$H(2)_{\mathrm{A}}$ : The macroeconomic situation has a significant effect on changes in the amount of MTPLI premiums;

3) $H(3)_{0}$ : The macroeconomic situation does not have a significant impact on the amount of MTPLI claims paid;

$H(3)_{\mathrm{A}}$ : The macroeconomic situation has a significant impact on the amount of MTPLI claims paid;

4) $H(4)_{0}$ : The macroeconomic situation does not have a significant impact on changes in the amount of MTPLI claims paid;

$H(4)_{\mathrm{A}}$ : The macroeconomic situation has a significant effect on changes in the amount of MTPL claims paid.

\section{Empirical results}

\subsection{Methods and data}

The objective of the study is to find out the macroeconomic indicators that determine the claims of MTPLI with a sufficiently high level of confidence and to assess the degree of impact of the relevant factors.

Based on the literature analysis and the study of macroeconomic indicators available in the databases (Eurostat, OECD and local Statistical Bureau), a list of variables was created for a more in-depth study of MTPLI claims paid (MTPLIC) volumes and growth rates using correlation analysis.
The simulation method was used to find out the relationships between the dependent variables (the amount and increase of MTPLIC) and the selected independent macroeconomic variables based on Latvian data for the period 2005-2020. Various combinations of factors as well as linear and nonlinear forms of relationships were tested. The statistical stability of the generated models was tested using the $F$-test, but the regression parameter stability was tested using $t$-tests. Durbin-Watson test was used to detect the presence of autocorrelation in the residuals. The best fit models were determined using the coefficient of determination $\left(R^{2}\right)$ and $p$-values.

\subsection{Macroeconomic indicators associations with MTPLI premiums and claims}

Based on the literature analysis and the study of macroeconomic indicators available in the databases (Eurostat, OECD and local Statistical Bureau), a list of variables was determined for a more in-depth study of MTPLI premiums (MTPLIP) volumes and growth rates for the period 2005-2020 using regression analysis methods, see the following table.

Table 1. Macro indicators correlation with MTPLIGP amounts and MTPLIGP growth.

\begin{tabular}{|l|l|l|r|r|}
\hline \multicolumn{1}{|c|}{ Factors } & \multicolumn{1}{c|}{$\begin{array}{c}\text { Unit of } \\
\text { measure }\end{array}$} & $\begin{array}{l}\text { Deno- } \\
\text { tation }\end{array}$ & $\begin{array}{l}\text { MTPLIP } \\
\text { amounts }\end{array}$ & $\begin{array}{c}\text { MTPLIP } \\
\text { growth }\end{array}$ \\
\hline Pass. cars & th. & $P C R$ & 0.8373 & 0.4440 \\
\hline Total cars & th. & $T C R$ & 0.8117 & 0.4512 \\
\hline HICP & y-o-y, \% & $H I C P$ & 0.7984 & 0.5784 \\
\hline HH debt & \% of GDP & $H D G$ & 0.6313 & -0.0511 \\
\hline Investments & \% of GDP & $I N V G$ & 0.5783 & 0.6611 \\
\hline Private debt & \% of GDP & $P S D$ & 0.5562 & -0.1729 \\
\hline L-T interest & $\%$ & $L T R$ & 0.5429 & -0.2300 \\
\hline Net wages & y-o-y, \% & $N W G$ & 0.4668 & 0.7977 \\
\hline GDP & $\mathrm{y}-\mathrm{o}-\mathrm{y}, \%$ & $G D P$ & -0.2821 & 0.4993 \\
\hline Unempl. & annual, \% & $U N P L$ & -0.1066 & -0.6653 \\
\hline HH disp.inc. & $\mathrm{y}-\mathrm{o}-\mathrm{y}, \%$ & $H D I G$ & -0.0783 & 0.6651 \\
\hline
\end{tabular}

Source: Calculated by authors based on [16] and [17].

As can be seen from Table 1, MTPLIGP volumes are most significantly affected by indicators such as passenger cars registered (PCR), total cars registered (TCR) and Harmonised Index of Consumer Prices (HICP), as shown by the correlation coefficients of $0.8373,0.8117$ and 0.7984 , respectively. The growth of the MTPLIGP, on the other hand, is most strongly influenced by indicators such as net wage growth (NWG), 
unemployment rate (UNPL) and household disposable income growth (HDIG), as shown by the correlation coefficients of $0.7977,-0.6653$ and 0.6651 , respectively.

Fig. 3 shows the associations of the major macro indicators with the MTPLIGP volumes.
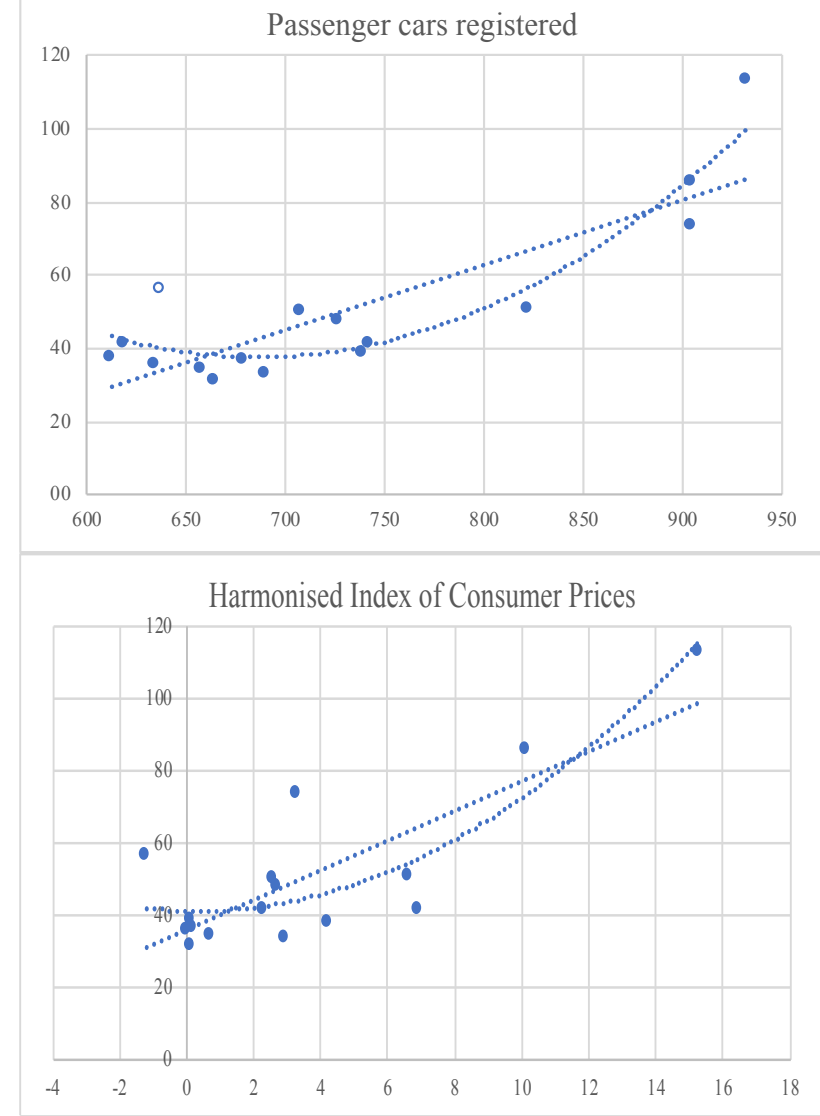

Household debt to GDP

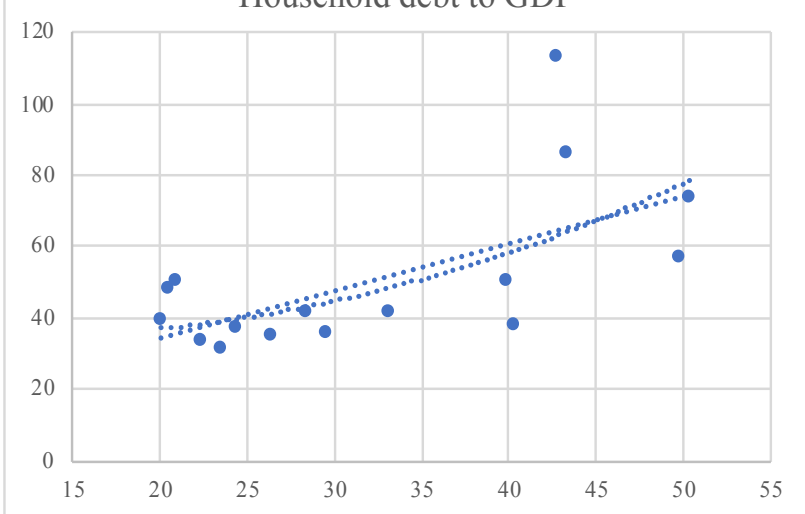

Fig. 3. Macro indicators and MTPLI gross premiums trends

Source: Created by authors, based on [16] and [17].

Consequently, we see that as PCR, TCR, HICP and $\mathrm{HH}$ debt to GDP increases, so do MTPLIGP premiums.
Let $M T P L I_{\mathrm{t}}$ be dependent variable in year $t$. Further,

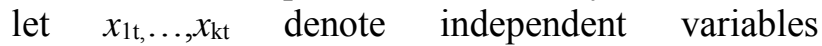
(macroeconomic indicators) and $b_{\mathrm{it}}, \ldots, b_{\mathrm{kt}}$ denote regression coefficients of independent variables, than the model can be expressed as in equation:

(1) $M T P L I_{t}=f\left(x_{1 t}, \ldots, x_{k t}\right)+\varepsilon_{t}$ where $\varepsilon_{t}$ - the error term.

During the research, combining the selected factors, linear and polynomial regression models were calibrated which passed the $F$-test at the confidence level of 0,95 and the Durbin Watson test with $\alpha=$ 0,05 .

\subsection{The impact of the macroeconomic environment on MTPLI premiums}

The following table summarizes the coefficients of determination, $F$-statistics and $p$-values for top 6 statistically significant models for MTPLIGP volumes.

Table 2. Top 6 regression models statistics

\begin{tabular}{|l|l|c|c|r|}
\hline $\begin{array}{c}\text { Model } \\
\text { type }\end{array}$ & Variables & $\boldsymbol{R}^{\mathbf{2}}$ & $\boldsymbol{F}$ & $\begin{array}{c}\boldsymbol{p} \text { - } \\
\text { value }\end{array}$ \\
\hline Polynomial & $T C R$ & 0.8824 & 48.75 & $<0.01 \%$ \\
\hline Polynomial & $P C R$ & 0.8691 & 43.15 & $<0.01 \%$ \\
\hline Polynomial & $H I C P$, LTR & 0.8593 & 39.71 & $<0.01 \%$ \\
\hline Polynomial & $H I C P, H D G$ & 0.8421 & 34.67 & $0.01 \%$ \\
\hline Polynomial & HICP & 0.7441 & 40.72 & $<0.01 \%$ \\
\hline Linear & HICP & 0.6374 & 24.61 & $0.02 \%$ \\
\hline
\end{tabular}

Source: Calculated by authors based on [16] and [17].

As one can see, the top 6 regression models explain more than $63 \%$, while the top for regression models explain at least $84 \%$ of the total MTPLI gross premiums variability. The $F$-test results show that the statistical stability of all top 6 models is high $(<0.03 \%)$, but the probability of statistical error of the first tree models is even lower than $0.01 \%$.

The following table summarizes the regression coefficients and $t$-test $p$-values for top 6 statistically significant models for MTPLIGP volumes.

Table 3. Top 6 regression models for MTPLIGP volumes variables statistics

\begin{tabular}{|c|l|r|r|}
\hline Model & Variable & Regr.coeff. & $p$ - value \\
\hline \multirow{2}{*}{1} & $T C R^{\wedge} 2$ & 0.0007 & $0.013 \%$ \\
\cline { 2 - 4 } & $T C R$ & -1.1851 & $0.032 \%$ \\
\hline \multirow{2}{*}{2} & $P C R^{\wedge} 2$ & 0.0010 & $0.064 \%$ \\
\cline { 2 - 4 } & $P C R$ & -1.4146 & $0.154 \%$ \\
\hline \multirow{2}{*}{3} & $H I C P^{\wedge} 2$ & 0.2863 & $0.001 \%$ \\
\hline
\end{tabular}




\begin{tabular}{|c|l|r|r|}
\hline & $L T R$ & 2.1787 & $0.309 \%$ \\
\hline \multirow{2}{*}{4} & $H I C P^{\wedge} 2$ & 0.2682 & $0.002 \%$ \\
\cline { 2 - 4 } & $H D G$ & 0.7187 & $0.695 \%$ \\
\hline 5 & $H I C P^{\wedge} 2$ & 0.3184 & $0.001 \%$ \\
\hline 6 & $H I C P$ & 4.1120 & $0.010 \%$ \\
\hline
\end{tabular}

Source: Calculated by authors based on [16] and [17].

As one can see from Table 3, the regression coefficients $t$-test $p$-values for all top 6 models do not exceed $0.7 \%$, indicating strong relationship between MTPLI gross premiums and relevant macro indicators. Therefore, it can be considered that confirmation of the rejection of the first null hypothesis has been obtained and the alternative hypothesis is valid - the macroeconomic situation has a significant impact on the amount of MTPLI premiums.

The following table summarizes the coefficients of determination, $F$-statistics and $p$-values for top 6 statistically significant models for MTPLIGP growth.

Table 4. Top 6 regression models for MTPLIGP growth variables statistics

\begin{tabular}{|c|l|c|c|c|}
\hline $\begin{array}{c}\text { Model } \\
\text { type }\end{array}$ & \multicolumn{1}{|c|}{ Variables } & $\boldsymbol{R}^{\mathbf{2}}$ & $\boldsymbol{F}$ & $\begin{array}{c}\boldsymbol{p} \text { - } \\
\text { value }\end{array}$ \\
\hline Polyn. & $N W G^{\wedge} 2, G D P$ & 0.7208 & 16.78 & $0.126 \%$ \\
\hline Linear & $I N V, \ln (G D P)$ & 0.7054 & 15.56 & $0.168 \%$ \\
\hline Polyn. & $\begin{array}{l}I N V G^{\wedge} 2, \\
\ln (G D P)\end{array}$ & 0.6956 & 14.86 & $0.199 \%$ \\
\hline Polyn. & $I N V G^{\wedge} 2, G D P$ & 0.6832 & 14.02 & $0.246 \%$ \\
\hline Linear & $\begin{array}{l}I N V G, \\
\ln (G D P)\end{array}$ & 0.6746 & 13.47 & $0.282 \%$ \\
\hline Linear & $I N V G, G D P$ & 0.6737 & 13.42 & $0.286 \%$ \\
\hline
\end{tabular}

Source: Calculated by authors based on [16] and [17].

As one can see from Table 4, the top 6 regression models explain more than $67 \%$, while the top two regression models explain almost $70 \%$ of the total MTPLIGP growth variability. The $F$-test results show that the statistical stability of all top 6 models is high $(<0.29 \%)$, but the probability of statistical error of the first tree models is even lower than $0.2 \%$.

The following table summarizes the regression coefficients and $t$-test $p$-values for top 6 statistically significant models for MTPLIGP growth.

Table 5. Top 6 regression models for MTPLIGP growth variables statistics.

\begin{tabular}{|c|l|r|r|}
\hline Model & Variable & Regr.coeff. & $p$ - value \\
\hline \multirow{2}{*}{1} & $N W G^{\wedge} 2$ & 0.0848 & $0.005 \%$ \\
\cline { 2 - 4 } & $G D P$ & 8.3411 & $1.066 \%$ \\
\hline \multirow{2}{*}{2} & $I N V$ & -0.0144 & $0.007 \%$ \\
\cline { 2 - 4 } & $\ln (G D P)$ & 434.0897 & $0.005 \%$ \\
\hline \multirow{2}{*}{3} & $I N V G^{\wedge} 2$ & 0.0946 & $0.006 \%$ \\
\cline { 2 - 4 } & $\ln (G D P)$ & 84.8434 & $0.330 \%$ \\
\hline \multirow{2}{*}{4} & $I N V G^{\wedge} 2$ & 0.0932 & $0.007 \%$ \\
\cline { 2 - 4 } & $G D P$ & 5.0428 & $0.438 \%$ \\
\hline \multirow{2}{*}{5} & $I N V G$ & 5.1496 & $0.009 \%$ \\
\cline { 2 - 4 } & $\ln (G D P)$ & 83.7577 & $0.439 \%$ \\
\hline \multirow{2}{*}{6} & $I N V G$ & 4.5992 & $0.011 \%$ \\
\cline { 2 - 4 } & $G D P$ & 0.0032 & $0.446 \%$ \\
\hline
\end{tabular}

Source: Calculated by authors based on [16] and [17].

As one can see from Table 5, the regression coefficients $t$-test $p$-values for all top 6 models do not exceed $1,1 \%$, indicating strong relationship between MTPLIGP growth and relevant macroeconomic indicators. Therefore, it can be considered that confirmation of the rejection of the second null hypothesis has been obtained and the alternative hypothesis is valid - the macroeconomic situation has a significant effect on changes in the amount of MTPLI premiums.

\subsection{The impact of the macroeconomic environment on MTPLI claims}

List of indicators for more in-depth study of MTPLI claims paid (MTPLIC) volumes and growth rates for the period 2005-2020 using regression analysis methods, see the following table.

Table 6. Macro indicators correlation with MTPLIC amounts and MTPLIC growth

\begin{tabular}{|l|c|l|l|l|}
\hline \multicolumn{1}{|c|}{ Factors } & $\begin{array}{c}\text { Unit of } \\
\text { measure }\end{array}$ & $\begin{array}{c}\text { Deno- } \\
\text { tation }\end{array}$ & $\begin{array}{c}\text { MTPLIC } \\
\text { amounts }\end{array}$ & $\begin{array}{c}\text { MTPLIC } \\
\text { growth }\end{array}$ \\
\hline MTPLIP & EUR mio & $M T G P$ & 0.9736 & 0.8748 \\
\hline Pass. Cars & th. & $P C R$ & 0.7950 & 0.4440 \\
\hline Total cars & th. & $T C R$ & 0.7614 & 0.4485 \\
\hline HICP & y-o-y, \% & $H I C P$ & 0.7593 & 0.5193 \\
\hline HH debt & \%of GDP & $H D G$ & 0.7111 & 0.0067 \\
\hline Gr.debt HH & \% of inc. & GDIH & 0,6789 & 0,0614 \\
\hline Private debt & \%of GDP & $P S D$ & 0.6451 & -0.1163 \\
\hline L-T interest & \% & LTR & 0.6046 & -0.1875 \\
\hline FDI stock & \%of GDP & $F D I$ & $-0,5991$ & $-0,4269$ \\
\hline Investments & \%of GDP & $I N V G$ & 0.5470 & 0.6680 \\
\hline Net wages & y-o-y, \% & $N W G$ & 0.4307 & 0.7928 \\
\hline Source Car
\end{tabular}

Source: Calculated by authors based on [16] and [17]. 
As can be seen from Table 6, MTPLIC volumes are most significantly affected by indicators such as MTPLI gross premiums (MTGP), passenger cars registered (PCR), total cars registered (TCR) and Harmonised Index of Consumer Prices (HICP), as shown by the correlation coefficients of 0.9736 , $0.7950,0,7614$ and 0.7593 , respectively. The growth of the MTPLIC, on the other hand, is most strongly influenced by indicators such as MTGP growth, net wage growth (NWG), investments to GDP (INVG), household disposable income growth (HDIG) and unemployment rate (UNPL) as shown by the correlation coefficients of $0.8748,0.7928$, $0.6680,0.6312$ and -0.6214 , respectively.

Fig. 4 shows the associations of the major macro indicators with the MTPLIC volumes.
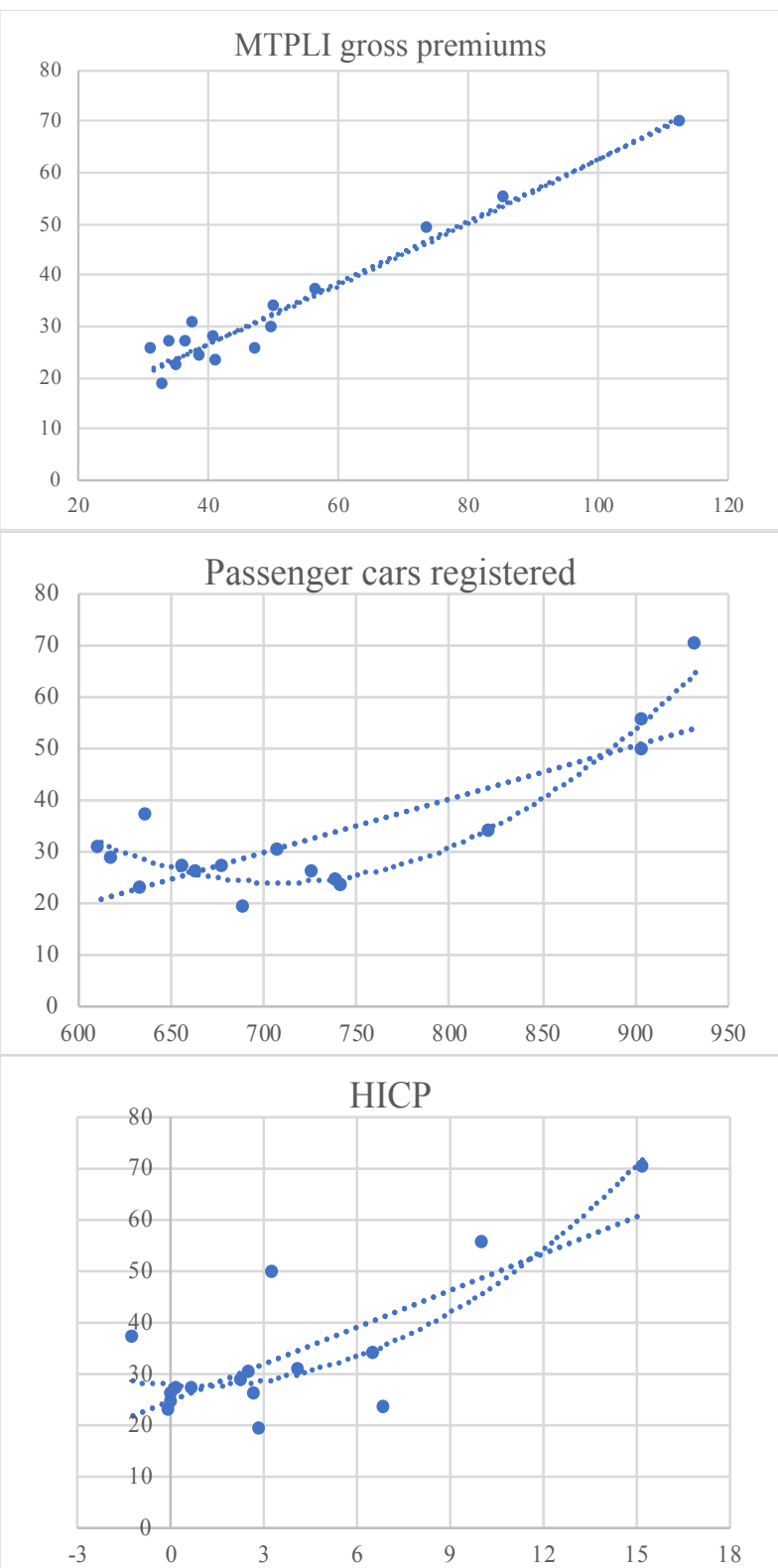

Fig. 4. Macro indicators and MTPLI claims paid trends
Source: Created by authors, based on [16] and [17].

Consequently, we see that as MTPLI gross premiums, passenger cars, total cars and HICP increases, so do MTPLI claims paid.

The following table summarizes the coefficients of determination, $F$-statistics and $p$-values for top 6 statistically significant models for MTPLIGP volumes.

Table 7. Top 6 regression models statistics

\begin{tabular}{|c|l|c|c|c|}
\hline $\begin{array}{c}\text { Model } \\
\text { type }\end{array}$ & Variables & $\boldsymbol{R}^{\mathbf{2}}$ & $\boldsymbol{F}$ & $\boldsymbol{p}$ - value \\
\hline Linear & $\begin{array}{l}M T G P, \\
\ln (G D I H)\end{array}$ & 0.9661 & 185.27 & $<0.01 \%$ \\
\hline Linear & $\begin{array}{l}M T G P, \\
\ln (P S D)\end{array}$ & 0.9651 & 179.11 & $<0.01 \%$ \\
\hline Linear & $\begin{array}{l}M T G P, \\
\ln (H D G)\end{array}$ & 0.9647 & 177.78 & $<0.01 \%$ \\
\hline Linear & $M T G P$ & 0.9479 & 254.61 & $<0.01 \%$ \\
\hline Polyn. & $P C R$ & 0.9228 & 77.69 & $<0.01 \%$ \\
\hline Polyn. & $T C R$ & 0.9104 & 66.94 & $<0.01 \%$ \\
\hline Source: & Cal & &
\end{tabular}

Source: Calculated by authors based on [16] and [17].

As one can see, the top 6 regression models explain more than $91 \%$, while the top three regression models explain at least $96 \%$ of the total MTPLI gross claims paid variability. The $F$-test results show that the statistical stability of all top 6 models is high $(<0.01 \%)$.

The following table summarizes the regression coefficients and $t$-test $p$-values for top 6 statistically significant models for MTPLI claims paid volumes.

Table 8. Top 6 regression models for MTPLI claims paid volumes variables statistics

\begin{tabular}{|c|l|r|r|}
\hline Model & Variable & Regr.coeff. & $p$ - value \\
\hline \multirow{2}{*}{1} & $M T G P$ & 0.5439 & $<0.01 \%$ \\
\cline { 2 - 4 } & Ln((GDIH) & 6.9394 & $1.012 \%$ \\
\hline \multirow{2}{*}{2} & $M T G P$ & 0.5466 & $<0.01 \%$ \\
\cline { 2 - 4 } & Ln(PSD) & 9.2225 & $1.259 \%$ \\
\hline \multirow{2}{*}{3} & $M T G P$ & 0.5384 & $<0.01 \%$ \\
\cline { 2 - 4 } & Ln(HDG) & 6.9148 & $1.350 \%$ \\
\hline \multirow{2}{*}{4} & $M T G P$ & 0.5996 & $<0.01 \%$ \\
\hline \multirow{2}{*}{5} & $T C R^{\wedge} 2$ & 0.0005 & $<0.01 \%$ \\
\cline { 2 - 4 } & $T C R$ & -0.9290 & $<0.01 \%$ \\
\hline \multirow{2}{*}{6} & $T C R^{\wedge} 2$ & 0.0008 & $<0.01 \%$ \\
\cline { 2 - 4 } & $T C R$ & -1.1582 & $<0.01 \%$ \\
\hline
\end{tabular}

Source: Calculated by authors based on [16] and [17]. 
As one can see from Table 8, the regression coefficients $t$-test $p$-values for all top 6 models do not exceed $1.4 \%$, indicating strong relationship between MTPLI claims paid and relevant macro indicators. Therefore, it can be considered that confirmation of the rejection of the third null hypothesis has been obtained and the alternative hypothesis is valid - the macroeconomic situation has a significant impact on the amount of MTPLI claims paid.

The following table summarizes the coefficients of determination, $F$-statistics and $p$-values for top 6 statistically significant models for MTPLI claims paid growth.

Table 9. Top 6 regression models for MTPLI claims paid growth variables statistics

\begin{tabular}{|c|l|c|c|c|}
\hline $\begin{array}{c}\text { Model } \\
\text { type }\end{array}$ & \multicolumn{1}{|c|}{ Variables } & $\boldsymbol{R}^{\mathbf{2}}$ & $\boldsymbol{F}$ & $\begin{array}{c}\boldsymbol{p}- \\
\text { value }\end{array}$ \\
\hline Polyn. & $\begin{array}{l}M T G P G^{\wedge} 2, \\
H D I G\end{array}$ & 0.7746 & 22.34 & $0.040 \%$ \\
\hline Linear & $M T G P G$ & 0,7652 & 45,63 & $<0,01 \%$ \\
\hline Polyn. & $\begin{array}{l}M T G P G^{\wedge} 2, \\
H D I\end{array}$ & 0.7539 & 19.92 & $0.064 \%$ \\
\hline Polyn. & $\begin{array}{l}M T G P G^{\wedge} 2, \\
N W G\end{array}$ & 0.7062 & 15.62 & $0.165 \%$ \\
\hline Polyn. & $\begin{array}{l}M T G P G^{\wedge} 2, \\
P S D\end{array}$ & 0.6809 & 13.93 & $0.241 \%$ \\
\hline Polyn. & $\begin{array}{l}M T G P G^{\wedge} 2, \\
U N P L\end{array}$ & 0.6679 & 13.08 & $0.313 \%$ \\
\hline
\end{tabular}

Source: Calculated by authors based on [16] and [17].

As one can see from Table 9, the top 6 regression models explain more than $66 \%$, while the top tree regression models explain more than $75 \%$ of the total MTPLI claims paid growth variability. The $F$ test results show that the statistical stability of all top 6 models is high $(<0.7 \%)$, but the probability of statistical error of the first two models is even lower than $0.1 \%$.

The following table summarizes the regression coefficients and $t$-test $p$-values for top 6 statistically significant models for MTPLI claims paid growth.

Table 10. Top 6 regression models for MTPLI claims paid growth variables statistics.

\begin{tabular}{|c|l|r|r|}
\hline Model & \multicolumn{1}{|c|}{ Variable } & Regr.coeff. & $p$ - value \\
\hline \multirow{2}{*}{1} & $M T G P G^{2}$ & 0.0143 & $0.026 \%$ \\
\cline { 2 - 4 } & $H D I G$ & 2.7850 & $0.032 \%$ \\
\hline 2 & $M T G P G$ & 0.9169 & $<0.01 \%$ \\
\hline 3 & $M T G P G^{\wedge} 2$ & 0.0142 & $0.041 \%$ \\
\hline
\end{tabular}

\begin{tabular}{|c|l|r|r|}
\hline \multirow{2}{*}{4} & $H G D I$ & 2.5305 & $0.058 \%$ \\
\hline \multirow{2}{*}{5} & $M T G P G^{\wedge} 2$ & 0.0078 & $4.331 \%$ \\
\cline { 2 - 4 } & $N W G$ & 1.8937 & $0.195 \%$ \\
\cline { 2 - 4 } & $M T G P G^{\wedge} 2$ & 0.0110 & $2.202 \%$ \\
\hline \multirow{2}{*}{6} & $M S D$ & 4.4169 & $2.465 \%$ \\
\cline { 2 - 4 } & $M T G P G^{\wedge} 2$ & 0.0129 & $0.276 \%$ \\
\cline { 2 - 4 } & $U N P L$ & -3.6316 & $0.458 \%$ \\
\hline
\end{tabular}

Source: Calculated by authors based on [16] and [17].

As one can see from Table 10, the regression coefficients $t$-test $p$-values for all top 6 models are below $5,0 \%$, indicating strong relationship between MTPLIGP growth and relevant macroeconomic indicators. Therefore, it can be considered that confirmation of the rejection of the fourth null hypothesis has been obtained and the alternative hypothesis is valid - the macroeconomic situation has a significant effect on changes in the amount of MTPL claims paid.

\section{Conclusion}

The COVID-19 crisis continues to have a significant impact on people, society, business and the wider economy around the world. The insurance industry has not been spared its impact, but insurers have responded quickly to the crisis. As the economy as a whole recovers and responds to the pandemic, insurers will face a number of challenges, but also see many new opportunities in the medium to long term.

The results of the study allow concluding that macroeconomic developments have a significant impact on both, MTPLI premiums and claims paid. The pandemic has had a much more significant impact on the amount of MTPLI premiums (-18\%) compared to the decrease in claims $(-6 \%)$. According to the study, macroeconomic indicators such as HICP, household debt, investments, GDP and net wages growth have the most statistically significant impact on MTPLI premiums. MTPLI's claims, on the other hand, are most affected by household disposable income, private sector debt, household debt, net wages growth and unemployment. MTPLI premiums and claims amounts and their changes can be explained by macroeconomic indicators with a high level of confidence. Consequently, business volume forecasts for the insurance industry and the companies operating in it can be reasonably compiled on the basis of macroeconomic 
development scenarios with a relatively high level of reliability.

However, it should be noted that no model is perfect by definition. In addition, both the level of macroeconomic development, as well as intercultural differences and the dynamics of the two, cause changes that cannot be ignored. Therefore, first, MTPLI models need to be calibrated based on local data and regularly updated, and second, it is desirable to maintain more than one regression model in order to be able to base forecasting on a set of macroeconomic indicators that cannot be included in the model at the same time due to their statistical incompatibility (noncompliance with regression analysis assumptions). In this way, using the predictions of several models and weighing them, e.g. based on $R^{2}$, it is possible to increase the reliability of the obtained results.

\section{References:}

[1] Beck, T. and Webb, I., Economic, Demographic, and Institutional Determinants of Life Insurance Consumption across Countries. The World bank economic review, vol. 17(1), 2003, pp. 51-88.

[2] Cavalcante, R.T., Sobreiro, V.A., Kimura, H., Determinants of the non-life insurance market in Brazil. Review of Development Finance, 8,2018, pp. 89-95.

[3] Chien-Chiang, L., Yi-Bin, C., International Review of Economics and Finance, Vol. 21, 2012, pp. 246-260.

[4] Dragos, S.L., Life and non-life insurance demand: the different effects of influence factors in emerging countries from Europe and Asia, Economic Research-Ekonomska Istraživanja, 27:1, 2014, pp. 169-180.

[5] Feyen, E. and Lester, R.R. and Rocha, R., What Drives the Development of the Insurance Sector? An Empirical Analysis Based on a Panel of Developed and Developing Countries (March 21, 2013). Journal of Financial Perspectives, 1(1), 2013.

[6] Hsu, Y.C., Chou, P.L., Shiu, Y.M., An examination of the relationship between vehicle insurance purchase and the frequency of accidents. Asia Pacific Management Review, 21, 2016, pp. 231-238.

[7] Lakštutienè A., Correlation of the Indicators of the Financial system and Gross Domestic Product in European Union Countries, Engineering economics, No. 3, (58), 2008.
[8] Lee, C.C., Chiu, Y.B., The impact of real income on insurance premiums- Evidence from panel data. International Review of Economics \& Finance, 21(1), 2012, pp. 246-260.

[9] Nakata, H., \& Sawada,Y., The Demand for Non-Life Insurance- A Cross- Country Analysis. CIRJE F-Series CIRJE-F-461, CIRJE, Faculty of Economics, University of Tokyo, 2007.

[10] Petkovski, M., Jordan, K., An analysis of non-life insurance determinants for selected countries in central and South Eastern Europe. A co-integration approach. Romanian Journal of Economic Forecasting, 17 (3), 2014, pp. 160178

[11] Pradhan, R.P., Arvin, M.B., Nair, M., Bennett, S.E., Unveiling the causal relationships among banking competition, stock and insurance market development, and economic growth in Europe. Structural Change and Economic Dynamics, 55, 2020, pp. 74-87.

[12] Pradhan, R.P., Dash, S., Maradana, R.P., Jayakumar, M. and Gaurav, K. , Insurance market density and economic growth in Eurozone countries- the granger causality approach. Financial Innovation, 3, 2017, pp. 1624.

[13] Sherden, W., An Analysis of the Determinants of the Demand for Automobile Insurance. Journal of Risk and Insurance, 51, 1984, pp. 49-62.

[14] Skalska, M., The relationship between insurance development and economic growth. The motor third party liability insurance in the Czech Republic. The 12th International Days of Statistics and Economics, Prague, September 68, 2018.

[15] Trinh, T., Nguyen, X. and Sgro, P., Determinants of non-life insurance expenditure in developed and developing countries: an empirical investigation, Applied economics, 48 (58), 2016, pp. 5639-5653.

[16] EUROSTAT, 2021. Database. Economy and Finance. Available: https://ec.europa.eu/eurostat/web/main/data/data base

[17] THE FINANCIAL AND CAPITAL MARKET COMMISSION., March 2021. Operations of Insurance companies in 4th Quarter of 2020. In: www.fktk.lv. Available: https://www.fktk.lv/en/statistics/insurance/quart erly-reports/

\section{Author Contributions:}


Aivars Spilbergs participated in development research methodology, performed analysis of associations between studied indicators and simulations, as well as evaluated the statistical stability of the models and regression coefficients.

Andris Fomins participated in the development and design of methodology. Creation of the work, specifically writing the initial draft was carried out. Preparation and creation of the published work with the colleagues of the research group, specifically critical review, commentary and revision was done.

Maris Krastins in cooperation with Latvian Insurers association organized MTPL insurance data obtaining from insurance market. As well, contribution to preparation of literature review was carried out.

\section{Sources of funding for research presented in a scientific article or scientific article itself}

This particular study has been funded by the Research Grant Fund of BA School of Business and Finance. The funding of the study does not in any way influence the development of the study's conclusions and proposals. 